\title{
perifèria
}

Número 7, Diciembre 2007

www.periferia.name

\section{Notas para una aproximación antropológica a los bancos de semillas locales}

\author{
Daniel Rementeria Arruza - UPV ${ }^{1}$
}

\section{Resumen}

Los avances en biotecnología genética y las políticas neoliberales de mercado han puesto al alcance de las grandes compañías multinacionales nuevos espacios de interés, como las semillas. En torno a estos "territorios interiores" están teniendo lugar toda una serie de procesos de puesta en valor, patrimonialización, apropiación, legislación y representación. A su vez, a nivel local proliferan por toda la geografía del planeta diferentes respuestas y fenómenos de recuperación y preservación de la biodiversidad genética y cultural, así como de los conocimientos tradicionales a ésta asociados, en forma de bancos de semillas autóctonas. Una de estas iniciativas impulsada por el grupo de voluntariado Galtzagorriak y el sindicato agrario EHNE se lleva a cabo en el marco de la reserva de la Biosfera de Urdaibai (Bizkaia) con la especificidad legislativa que le da el Plan de Uso y Gestión de la Reserva.

La antropología socio-cultural nos ofrece distintos marcos de análisis para acercarnos a las diversas caras que presenta esta problemática medioambiental a nivel social, cultural, político y representacional. En estas notas se recoge un esbozo de enfoque teórico para abordar estos fenómenos.

Palabras clave: Antropología, semillas, patrimonio, legislación, ecología.

\section{Abstract}

Advances in genetic biotechnology and neoliberal market policies have opened new spaces for the big multinational firms' interests, such as seeds. A process of appropriation, valuation, legislation and representation is taking place around these "interior territories". At the same time, locally different answers are given and different initiatives are taken all around the world for genetic and cultural biodiversity and knowledge preservation, in the form of local seed banks. One of these initiatives, impelled by Galtzagorriak voluntaries group and EHNE agrarian syndicate, is carried out in the Urdaibai Biosphere Reserve under the specific legislation of the Reserve's Use and Management Plan.

Social and cultural anthropology gives us different points of view for the analysis of the multiple sides of this environmental problem in its social, cultural, political and representational aspects. These notes are an outline of a theoretical approach to these phenomena.

Keywords: Anthropology, seeds, patrimony, legislation, ecology.

\footnotetext{
${ }^{1}$ Antropólogo Social y Cultural. Investigador predoctoral en la Universidad del País Vasco.
} 


\section{perifèria}

Número 7, Diciembre 2007

www. periferia.name

\section{I ntroducción}

Los continuos avances en biotecnología y las políticas neoliberales de mercado han propiciado toda una problemática de carácter mundial en torno a las semillas, su producción, conservación, selección y comercialización. La biotecnología genética ha puesto al alcance de las grandes compañías multinacionales nuevos espacios de interés en torno a los que están teniendo lugar procesos de puesta en valor, patrimonialización, apropiación, legislación y representación.

A su vez, a nivel local proliferan por toda la geografía del planeta diferentes respuestas y fenómenos de recuperación y preservación de la biodiversidad genética y cultural, así como de los conocimientos tradicionales a ésta asociados, en forma de bancos de semillas autóctonas y demás movimientos agrarios e indigenistas y de organizaciones no gubernamentales. La antropología sociocultural nos ofrece diferentes marcos de análisis para acercarnos a las distintas caras que presenta esta problemática medioambiental:

1) Con la biotecnología genética las semillas se perfilan como vastos espacios sobre los que actuar a nivel material, espacios interiores como sugiere Vandana Shiva (2001) susceptibles de apropiación o colonización. La antropología jurídica nos ofrece una perspectiva desde la que analizar la regulación legislativa de todo este proceso en base a leyes de propiedad intelectual y patentes sobre la biodiversidad genético-cultural y el conocimiento tradicional, en contraposición a los sistemas de propiedad comunal tradicionales de las comunidades donde se encuentran los grandes centros de la diversidad genética mundial. El acceso a los recursos genéticos, o el derecho medio ambiental son cuestiones relacionadas con los derechos de los pueblos indígenas y comunidades locales susceptibles de abordarse desde esta perspectiva.

2) La dinámica mercantilista asociada al "progreso" biotecnológico ha puesto en valor tanto el material genético como el conocimiento tradicional asociado a su uso. Este proceso de patrimonialización tiene lugar tanto desde los intereses mercantiles aparentemente paradójicos de las multinacionales 


\section{perifèria}

Número 7, Diciembre 2007

www.periferia. name

semilleras, como desde los intereses de las propias comunidades locales e indígenas en defensa del expolio al que se ven sometidas. El tratamiento del concepto de patrimonio cultural que se propone desde la antropología sociocultural va más allá del propio objeto material, para ocuparse concretamente de las representaciones que en torno a ese objeto construyen los individuos y comunidades que lo utilizan.

3) Los procesos de apropiación tienen un componente simbólico representacional asociado fundamental en la territorialización de los espacios. La semilla se ha convertido en un espacio sobre el que elaborar representaciones, imágenes culturales que completen de alguna manera la apropiación de esos espacios donde es posible trazar una línea fronteriza entre naturaleza y cultura. En este sentido, la antropología ecológica nos da algunas claves para abordar, las formas de relación del ser humano con su entorno medio ambiental, las formas de usarlo, entenderlo y representarlo. $Y$ nos ofrece un marco para la reflexión en torno a uno de los clásicos binomios de la antropología: naturaleza/cultura.

En definitiva, una aproximación antropológica a este fenómeno con dimensiones a nivel global y local, macro y micro abarca cuestiones como derechos de los pueblos y comunidades locales, sistemas de propiedad tradicional, antropología jurídica, soberanía productiva y alimentaria, procesos de patrimonialización de la biodiversidad genético-cultural y del conocimiento tradicional, antropología del patrimonio, aspectos representacionales de la apropiación espacial, antropología ecológica; límites entre naturaleza y cultura.

\section{Acerca del Problema}

Ya en 1975, el antropólogo francés Claude Meillassoux se quejaba de lo raro que era encontrar en la literatura etnológica detalles sobre el acceso a las semillas (1993:64). Aparentemente la situación no ha cambiado mucho, si bien en nuestros días los trabajos de la física hindú Vandana Shiva ${ }^{2}$ nos ofrecen una perspectiva

\footnotetext{
2 Vandana SHIVA, Monocultivos y biotecnología (1994); Biopiratería: el saqueo de la naturaleza y del conocimiento (2001) y Cosecha robada. El secuestro del suministro mundial de alimentos (2003).
} 


\section{perifèria}

Número 7, Diciembre 2007

www. periferia.name

actual y global del problema que ha supuesto la reciente aparición en el mercado del uso intensivo de biotecnología, la aplicación de los derechos de propiedad intelectual y las patentes sobre la semilla y el conocimiento a estas aplicado tradicionalmente.

En las últimas décadas ha tenido lugar una profunda reestructuración del sector agrícola a nivel mundial, guiada por enormes corporaciones transnacionales que regulan la producción, el procesamiento, el comercio y el consumo a escala mundial. Algunos autores definen esta nueva revolución industrial y agrícola como un nuevo acto de confinamiento en referencia expresa al modo en que se resolvió la revolución agrícola de finales del siglo XVIII con el confinamiento de territorios por parte de terratenientes (Gillies, A. 1997). Este nuevo "acto de confinamiento" por parte del sector privado y las corporaciones transnacionales se basa en la expropiación de terrenos comunes en lo intelectual, como el conocimiento y técnicas de los pueblos agricultores e indígenas, y la creación de monopolios sobre muchos procesos biológicos y formas de vida, entre ellas las semillas, a través del uso de la propiedad intelectual, de la privatización de la biodiversidad y el conocimiento indígena y local a esta asociado.

Son tres los procesos que en la actualidad están haciendo más intenso el control de los monopolios sobre este primer eslabón de la cadena alimentaria que son las semillas: 1) la concentración económica; 2) la ingeniería genética, 3) las patentes y derechos de propiedad intelectual. El uso de monocultivos promovido por la agricultura industrial en su necesidad de mantener un control centralizado y monopólico sobre la producción y la distribución de alimentos, establece un refuerzo mutuo entre monocultivos y monopolios empresariales.

1) Concentración económica. La fuerza económica que impulsa este nuevo acto de confinamiento es la industria de la biotecnología, llamada también industria de la vida. El argumento más recurrente entre los defensores de la biotecnología, es el de presentar las nuevas tecnologías como la panacea ante la hambruna mundial, defendiendo la idea de que son imprescindibles para alimentar a las grandes bolsas de población pobre del mundo. La concentración económica no es un fenómeno nuevo en este sector. Ya en los años 70 y 80 tuvo lugar una permanente reducción 


\section{perifèria}

Número 7, Diciembre 2007

www. periferia. name

en el número de empresas que dominaban la agroindustria y el comercio farmacéutico. En poco tiempo, a través de sucesivas fusiones y adquisiciones de pequeñas empresas, subsidiarias y divisiones de otras empresas, las grandes compañías agroquímicas han ido conformado verdaderos gigantes empresariales ${ }^{3}$.

Estas empresas se redefinen así como "empresas de las ciencias de la vida". EI comercio de la soja al igual que el de otros productos agrícolas está controlado por seis Mercaderes del Grano: Cargill, Continental, Louis Dreyfus, Bunge, MitsuiCook y Andre\&Company. Pero no solo controlan el comercio de la soja, sino también el cultivo a través de las patentes.

Las empresas multinacionales agroquímicas y productoras de semillas, han desarrollado dos estrategias básicas para asegurarse el control de la producción de semillas. Por un lado tecnológicas (híbridos y transgénicos). Por otro, legales a través de los DPI, derechos de propiedad intelectual.

2) Ingeniería genética. Alterando una variedad de semilla concreta a través de la incorporación de un gen creado en laboratorio, las compañías han conseguido la patente exclusiva de esa variedad de semilla entera. En ocasiones, ante la imposibilidad de patentar determinadas semillas o técnicas, lo que hacen las multinacionales es añadir algunos elementos o "mejoras" adicionales. Todo esto genera una situación perversa y paradójica: los campesinos de las comunidades pobres sólo pueden acceder (sin infringir la ley) a unas semillas y procesos productivos que siempre han utilizado libremente, si previamente pagan los derechos derivados del uso de las patentes.

\footnotetext{
3 Los más destacables son los siguientes: Monsanto (EEUU, fusionó en 2005 el Guipo Pulsar/Seminis/ELM de México e incluye compañías como Calgene o Cargill de EEUU, dueña de Continental), Du Pont/Pioneer (EEUU), Syngenta (Suiza, fusión de Novartis, Sandoz y Ciba Geigy y Astra/Zeneca), Group Limagrain (Francia), Bayer (Alemania, fusionó Aventis CropScience formada por la fusión en 1999 de Hoechst y Rhone Poulenc. Incluye AgrEvo o Sunseeds), Advanta (Reino Unido/Holanda que trabaja para Syngenta Limagrain y Monsanto), Sakata (Japón), KWS/AG (Alemania), Takii (Japón), o Sungene (BASF, Alemania) y otras compañías farmaceúticas como Merck (EEUU), Bristol Myers (EEUU) o Pfizer (EEUU).
} 


\section{perifèria}

Número 7, Diciembre 2007

www. periferia. name

Diez compañías controlan el $100 \%$ del mercado de semillas genéticamente modificadas y el $32 \%$ del mercado de semillas comerciales del mundo ${ }^{4}$, pero también controlan el mercado agroquímico y de pesticidas del mundo. Los riesgos medioambientales que supone la utilización de organismos genéticamente modificados (OGM) ya se han hecho patentes en algunas latitudes y muestran lo lejos que están de la sostenibilidad (Wan Ho, 2001).

Con el tiempo se ha ido elaborando un gran mito empresarial, según el cual la agricultura industrial es necesaria para cultivar más alimentos y reducir el hambre en el mundo, ocultando sin embargo la creación de escasez tras una máscara de crecimiento. Dar de comer al mundo. Ese es el lema principal de la industria biotecnológica. Pero la imagen según la cual los cultivos modificados genéticamente son sostenibles es una ilusión fabricada por las grandes compañías. La agricultura industrial y la ingeniería genética aplicada a la agricultura, aumentan la producción a base de eliminar la parte de nutrición que le corresponde a la naturaleza y de aumentar los inputs externos, en forma de pesticidas, herbicidas y fertilizantes sintéticos fabricados por las mismas compañías.

Tradicionalmente la semilla ha sido producto y medio de producción a la vez (Kloppenburg, 1988), es decir semilla y grano. Para la agricultura productiva en cambio se trata de un mero insumo más (un bien empleado en la producción de otros bienes). A través de la biotecnología se somete a las semillas a un proceso de doble colonización fraccionando esa unidad con dos caras, fuente de alimento y medio de producción. Las nuevas biotecnologías se sustentan sobre la representación de la semilla como un elemento pasivo y la ubicación de la actividad y la creatividad en la mente del ingeniero de laboratorio, en lugar de en las dinámicas propias de la naturaleza.

Pero la ingeniería genética trabaja conjuntamente en perfecta complementariedad con todo un nuevo sistema de patentes aplicados a la vida, surgido del concepto eurocéntrico de propiedad.

\footnotetext{
${ }^{4}$ Vandana Shiva (2003):
} 


\section{perifèria}

Número 7, Diciembre 2007

www. periferia.name

3) Patentes. La aplicación de los derechos de propiedad intelectual sobre las semillas y el conocimiento a estas asociado está teniendo una serie de consecuencias graves en el sector: a) el agricultor pierde control sobre el primer eslabón de la cadena productiva, y se somete a una dependencia tecnológica y económica; b) se limita el flujo e intercambio libre de semillas, incrementándose su precio e imponiendo regalías y tasas tecnológicas a los agricultores; c) aumenta la erosión genética y cultural; d) se promociona el uso de semillas genéticamente modificados, con todas las implicaciones que esto conlleva en materia de bioseguridad y riesgos medioambientales desconocidos.

Esta dinámica legal impone a I@s agricultores todo tipo de condicionamientos a la hora del cultivo, prohibiéndoles guardar e intercambiar las semillas de su propia cosecha, y legitima un nuevo expolio de los bienes y del saber colectivo de las comunidades indígenas y locales o tradicionales. En definitiva, posibilita la privatización de recursos biológicos, de técnicas tradicionales (en muchos casos, milenarias) y de saberes colectivos de comunidades que pertenecen al dominio público. Los agricultores pasan así de ser los productores, a ser consumidores de productos agrícolas de las grandes compañías, que se convierten en los secuestradores de la alimentación mundial.

Por un lado como ya hemos visto, mediante las tecnologías de hibridación se elimina la capacidad reproductora de la semilla y se obliga a I@s agricultores a recurrir año tras año a proveedores de semillas mejoradas genéticamente. Por otro lado, a través de la normativa de derechos de propiedad intelectual fundamentados en la presunción de propiedad, al tiempo que se asegura la exclusividad en su utilización, se devalúa el proceso creativo de mejora anterior llevada a cabo por los agricultores durante siglos.

Hoy día hay básicamente dos tendencias que resumen los diferentes puntos de vista sobre el tratamiento que debería darse a las semillas autóctonas, el saber popular y los derechos de I@s agricultor@s. Por un lado, la tendencia dominante es el desplazamiento de la diversidad local vegetal sustituida por variedades patentadas. Las instituciones internacionales, presionadas por las grandes compañías del sector, están impulsando los regímenes de derechos de propiedad 


\section{perifèria}

Número 7, Diciembre 2007

www. periferia.name

intelectual. Los avances más destacados en este sentido han tenido lugar en el GATT (Acuerdo general sobre aranceles y comercio. Ronda de Uruguay) especialmente en relación con el acuerdo sobre TRIP (Derechos de Propiedad Intelectual Relacionados con el Comercio) y sobre agricultura. Otros dos foros importantes en esta línea han sido en 1991, la Convención Internacional sobre Protección de Obtenciones Vegetales y en 1992 la declaración del Grupo Consultivo de Investigación Agrícola Internacional.

Por otro lado, hay numerosas iniciativas en todo el mundo que reconocen el valor intrínseco de las semillas y la biodiversidad, así como la contribución de I@s agricultor@s a la innovación agrícola y a la conservación de las semillas y que perciben las patentes como una amenaza. A nivel mundial los foros más importantes en este sentido son la Comisión de Recursos Genéticos Vegetales de la FAO, y el Diálogo Keystone. Además habría que añadir la multitud de iniciativas que a nivel comunitario se están llevando a cabo en Asia, África, América Latina y Europa, para guardar y regenerar las semillas autóctonas.

Este panorama ha provocado distintas reacciones de los agricultores de todo el mundo en defensa de su medio y sus condiciones de vida, con discursos y representaciones diversas en torno a las nociones de naturaleza y sostenibilidad. Actualmente toma forma un movimiento orgánico internacional en continuo crecimiento que aboga de manera consciente por la evitación de sustancias químicas y de la ingeniería genética. Otra iniciativa en esta dirección de reivindicación de democracia alimentaria tiene que ver con las reclamaciones hechas para rescatar la simiente del control exclusivo al que está sometida por parte de las grandes compañías y la creación de bancos de semillas locales.

Un ejemplo de esto es Navdanya, una red nacional de la India para la creación de Bancos de semillas de las comunidades, orientada a proteger la diversidad de las semillas indígenas y con ellas el patrimonio intelectual común a estas comunidades. En los sistemas agrícolas montañosos del Himalaya de Garhwal, existe un patrón de cultivo particular llamado baranaja, que significa literalmente, doce semillas. Se mezclan las semillas de doce o más productos de cultivo diferentes y luego se siembran al azar en un campo fertilizado con excrementos de vaca y estiércol de 


\section{perifèria}

Número 7, Diciembre 2007

www. periferia.name

granja.

El movimiento Navdanya ha fundado 16 bancos de semillas en seis estados de la India. Este movimiento contra los cultivos y los alimentos genéticamente manipulados es hoy en día un movimiento ciudadano a escala mundial que integra a agricultores, consumidores activistas y científicos. El desarrollo de la biotecnología y los cultivos y alimentos transgénicos ha generado la resistencia de consumidores, productores agrícolas, movimientos sociales y activistas académicos por todo el mundo. Por otra parte, los efectos de la ingeniería genética y de los insumos agroquímicos asociados a la producción sobre el medio ambiente, los seres humanos y la diversidad biológica y cultural, es un tema que ha generado una gran producción de discursos y debates en las sociedades modernas (James, A. 1993).

La protección del saber indígena implica reconocer también los derechos comunitarios sobre la biodiversidad y la contribución de I@s agricultor@s y de los pueblos indígenas al proceso de evolución y protección de la biodiversidad tratando su saber como un sistema de conocimiento de futuro, a fin de que las generaciones futuras puedan disponer y acceder libremente a ese saber en la práctica diaria. Esta postura de protección y recuperación de la biodiversidad como bien comunal tiene una implicación política y social, pues reconoce la creatividad intrínseca de las distintas formas de vida y reclama y persigue el reconocimiento de un régimen de comunales para el patrimonio intelectual bajo la figura de los $\mathrm{DCl}$, derechos colectivos de propiedad intelectual, basados en la idea de biodemocracia y que reflejen distintas formas de generación y difusión del conocimiento.

En definitiva, el conflicto generado en torno a la biodiversidad oscila entre las nociones de propiedad privada o la comunal (comunitaria), y entre la utilización global o local de esa biodiversidad. Uno de los componentes esenciales de la globalización es el cultivo de lo uniforme que implica la homogeneidad y la destrucción de la diversidad a nivel ecológico pero también a nivel social y cultural. Los movimientos de revitalización de lo local, lo regional, lo religioso, y de lo étnico, son en gran medida movimientos de respuesta a la homogeneización y la uniformidad. En la actualidad el proceso de globalización y homogeneización es impulsado por fuerzas económicas globales que controlan los mercados, a través de 


\section{perifèria}

Número 7, Diciembre 2007

www.periferia. name

la metáfora económica del libre comercio. De esta forma la OMC a través de acuerdos internacionales como el GATT (Acuerdo general sobre aranceles y comercio), no solo regula el comercio internacional, sino que determina la política doméstica de los países simplemente añadiendo la coletilla "relacionado con el comercio" a cuestiones que atañen al ámbito doméstico. Esta política convierte en delitos todas aquellas acciones que se llevan a cabo en defensa de la diversidad biológica y cultural.

\section{Legislación Comercial, Leyes de Semillas}

A la legislación que atañe al proceso productivo en forma de derechos de propiedad intelectual y patentes, hay que añadir las llamadas leyes de semillas que hacen referencia a las reglamentaciones que regulan la comercialización de semillas, definiendo concretamente que materiales pueden venderse en el mercado y bajo qué condiciones. Ambos tipos de legislación se implementan y refuerzan mutuamente creando toda una estructura legislativa que mantiene y legitima la situación actual del sector.

A través de estas leyes se establece el marco institucional y legal de los consejos nacionales de semillas y las agencias de certificación, con el fin de regular tres aspectos básicamente: 1) el sistema de liberación de variedades de valor comprobado a través del sistema formal de semillas; 2) la certificación para controlar la identidad y pureza de las variedades; y 3) el control de calidad de semillas (pureza, viabilidad, sanidad) que busca proteger al productor de semillas de buena fe (Louwaars, 2005:5) frente a la competencia poco escrupulosa.

Las leyes de semillas por tanto reglamentan la liberación, la certificación y el control de calidad. Lo más común es que solamente obliguen a registrar y certificar la semilla que se comercializa. Sin embargo en muchos casos van más allá de la pura reglamentación de estos aspectos, prohibiendo el almacenamiento y posterior intercambio de semillas de la propia cosecha. En este sentido, en las leyes más extremas, el término semilla es utilizado en un sentido amplio abarcando cualquier parte de cualquier especie vegetal. 


\section{perifèria}

Número 7, Diciembre 2007

www.periferia. name

El mercado local produce y sustenta la diversidad pero los agricultores se van volviendo paulatinamente dependientes del modelo agrícola propuesto desde la cadena agroindustrial por los productores industriales de semillas. Francia tiene quizá la legislación más coercitiva del mundo en este sentido (Kästler, 2005) mantenida bajo la falaz excusa de la protección de la seguridad del consumidor y que realmente mantiene el monopolio absoluto sobre la producción de semillas por parte del estado y las compañías semilleras. Desde el año 1949, los agricultores franceses únicamente pueden comprar semilla registrada oficialmente en el catálogo nacional creado en 1932.

Pero por otro lado también existe gran cantidad de agricultores que prefieren no plantar cultivos que estén en el catálogo oficial de semillas, por diversas razones que van desde la mayor autonomía a la intención de crear sistemas agrícolas alternativos orgánicos, de bajos insumos, regionales o comarcales, basados en técnicas tradicionales de conservación y selección de semillas, sistemas agrícolas que mantengan un equilibrio con el medio ambiente, demanda por otro lado cada vez más creciente en la sociedad europea.

\section{Semillas, Nuevos Espacios de Apropiación. Territorios I nteriores}

\footnotetext{
La biotecnología, doncella del capital en la era postindustrial hace posible la colonización y el control de lo autónomo, lo libre y lo autorregenerativo. Mediante la ciencia reduccionista, el capital puede alcanzar espacios a los que nunca había accedido (Shiva, 2001:67).
}

La noción de territorio que se maneja desde la geografía cultural o de la percepción está ligada al concepto de apropiación (Bonnemaison, 1981; Di Méo, 2000), de forma que se entiende por territorio el espacio apropiado y valorizado por un grupo social para asegurar su reproducción y la satisfacción de sus necesidades vitales, tanto materiales como simbólicas.

En antropología dos son los niveles de análisis de la organización del territorio en base a esta idea de apropiación: por un lado la acción de los seres humanos sobre los soportes materiales de su existencia; por otro el de los sistemas de representación. Bonte, en su diccionario de antropología a propósito del concepto de territorio sugiere que, está a la vez objetivamente organizado y culturalmente 


\section{perifèria}

Número 7, Diciembre 2007

www. periferia. name

inventado (Bonte, 1996). Cada sociedad constituye en territorio el espacio que ocupa actuando sobre los componentes naturales de su medio. Sobre estos soportes materiales se aplican a su vez conocimientos, ideas y valores.

La apropiación del espacio no tiene sólo un carácter instrumental sino también simbólico, de forma que la cultura entendida como una trama de significados (Geertz, 2003:20) se constituye en una dimensión básica para entender este proceso y su resultado.

En el pasado, la teoría económica liberal del libre mercado propició la reducción conceptual de las personas en meros recursos humanos y de la tierra en recursos naturales, despojando a ambos de cualquiera otra de sus dimensiones y convirtiendo a la tierra y el trabajo en simples mercancías. En la actualidad, la dinámica de las transnacionales va más allá en el intento de reducir la biodiversidad de la naturaleza y la vida a meros recursos genéticos, reclamando incluso derechos de propiedad y explotación sobre los mismos. El término recursos genéticos, agrupa a toda una serie de materiales vivientes: semillas, microorganismos, genes, embriones animales, líneas celulares humanas y animales.

A la hora de hablar de patentes sobre seres vivos, hay que hacer notar que los derechos no solo se refieren a la apropiación del material genético propiamente, sino también a la descendencia del organismo patentado y por tanto a las funciones reproductivas de la vida. En este sentido, las patentes tendrían que ver más con la ocupación de nuevos territorios no colonizados, que con la innovación científica en pro de la erradicación del hambre mundial.

La legislación sobre DPI del GATT y de la OMC se fundamenta en la misma noción eurocéntrica de propiedad con la que se llevó a cabo la colonización de América, África y Asia. Ahora en cambio, los espacios colonizables son los códigos genéticos de los seres vivos es decir, espacios interiores. El capital liberal tiene ahora en estos espacios interiores de los cuerpos de las mujeres, plantas y animales, nuevas colonias que invadir y explotar para continuar el proceso de acumulación y control de la vida. 


\section{perifèria}

Número 7, Diciembre 2007

www. periferia. name

\section{El Conocimiento Tradicional y Propiedad I ntelectual}

En los tratados bilaterales regionales de libre comercio (TLCs) aparecen cada vez con mayor frecuencia disposiciones relativas al conocimiento tradicional de los pueblos indígenas y de las comunidades locales. La actual proliferación de este tipo de Tratados $^{5}$, los ha convertido en la gran amenaza para el conocimiento tradicional, pues en ellos los países depositarios de la biodiversidad negocian el acceso de investigadores (entre ellos muchos antropólogos) y empresas a la biodiversidad y al conocimiento tradicional de cada país formulado en términos de propiedad intelectual, es decir en términos de mercancías que es posible comprar y vender (Rodríguez, 2006). A finales del 2005, había en marcha en todo el mundo, alrededor de 240 procesos de negociación de TLCs.

El conflicto surge en el momento en el que entran en relación el conocimiento tradicional y el libre mercado y se manifiesta entre aquella postura que lo considera algo susceptible de comprarse y venderse y por otro, aquella que considera que debe permanecer al margen del mercado. Este conflicto cultural e ideológico es posible formularlo en términos de considerar el conocimiento tradicional como una propiedad intelectual susceptible de ser usado con fines económicos o comerciales, o considerarlo como patrimonio colectivo de pueblos y comunidades.

Existe una tendencia concreta en el derecho internacional sobre la regulación del conocimiento tradicional. Los países industrializados en su mayoría se muestran reticentes a cualquier acuerdo internacional que regule el problema a nivel mundial, mientras siguen obteniendo ganancias suculentas de la utilización comercial del conocimiento tradicional y la agenda neoliberal de privatizaciones va penetrando lenta pero sistemáticamente en el resto de países en desarrollo que son en general los depositarios de la codiciada biodiversidad. Todas las disposiciones sobre el conocimiento tradicional que aparecen en estos tratados siguen un patrón

\footnotetext{
${ }^{5}$ Algunos de estos tratados que incluyen disposiciones relativas al conocimiento tradicional son entre otros, el ALCA Acuerdo de Libre Comercio de las Américas, el TLCAN Tratado de Libre Comercio de América del Norte o NAFTA, el SAFTA Tratado de Libre Comercio del Sudeste Asiático, o el ECOTA Organización para la Cooperación Económica, que abarca Asia Central y Occidental y paises como Afganistán, Azerbaiján, Irán, Kazajstán, República Kirguiz, Pakistán, Tayikistán, Turquía, Turkmenistán y Uzbekistán.
} 


\section{perifèria}

Número 7, Diciembre 2007

www.periferia. name

determinado (Rodríguez, 2006) que expresa la preocupación fundamental de estos gobiernos firmantes de países en desarrollo en proteger el conocimiento tradicional que atesoran, deteniendo la apropiación indebida de este conocimiento, práctica que se conoce con el nombre de biopiratería. Por otro lado, en muchas ocasiones tiene lugar una especie de trampa dialéctica, en la que se incurre al tratar de defender los derechos colectivos a compartir, mejorar y desarrollar el conocimiento en el contexto local desde el marco predominante de la propiedad privada lo que conduce a generar propuestas y promover derechos sobre el conocimiento desde formulas adaptadas de derechos de propiedad intelectual, es decir desde un régimen de derechos monopólicos exclusivos para producir, utilizar, comprar y vender aquello que se suponga una innovación. Estos intentos se llevan a cabo generalmente con propuestas que suponen una nueva vuelta de tuerca a los derechos de propiedad intelectual y que dan lugar a otras figuras jurídicas como los derechos de autor o las marcas comerciales e indicaciones geográficas.

Varias cuestiones son comunes a este tratamiento del conocimiento tradicional, local o indígena en los tratados de libre comercio. Por un lado, se le otorga valor económico por lo que se puede considerar un asunto comercial. Se lo coloca dentro del dominio de lo privado por lo tanto es susceptible de tener dueños, y de ser regulado desde las leyes de la propiedad intelectual. Por tanto, también se puede proteger a través de las distintas normas que regulan los derechos de propiedad intelectual.

En definitiva, los países del Sur intentan utilizar los TLCs para compensar de alguna forma los acuerdos internacionales multilaterales sobre derechos de propiedad intelectual en cuestión de biodiversidad y conocimientos tradicionales tomados en el marco de la OMC. Sin embargo, los TLCs entre países del Norte y del Sur por lo general imponen a los países en desarrollo normas y compromisos dentro del campo de la propiedad intelectual para la gestión de este patrimonio, lo cual supone adoptar el origen mismo del problema para su solución. 


\section{perifèria}

Número 7, Diciembre 2007

www. periferia.name

\section{Patrimonio y Semillas}

A diferencia del tratamiento que se propone desde la perspectiva historiko-artística, centrado en el objeto, la antropología social y cultural nos propone un acercamiento al patrimonio cultural, trascendiendo el objeto en si (material o inmaterial), y centrado en las representaciones que del mismo hace la gente de la comunidad vinculada a dicho objeto y en los procesos de legitimación de algo como "patrimonio cultural". Desde este punto de vista, el concepto de patrimonio implica una construcción, convertir algo en patrimonio a partir de una valoración subjetiva del objeto en cuestión, y una legitimación por lo general sujeta a relaciones de poder.

Llorenç Prats (2005) distingue dos fases distintas, pero complementarias y sucesivas en los procesos de patrimonialización. Una basada en lo que este autor denomina la sacralización de la externalidad cultural, y otra consecuente basada en la puesta en valor o activación.

El patrimonio sería un sistema de representaciones, basado en ese mecanismo de sacralización de la externalidad cultural, constituido por metonimias, objetos, lugares o manifestaciones, procedentes de la naturaleza, del pasado o de la genialidad, que aparece con el desarrollo del capitalismo y la revolución industrial, y se apoya en su creciente separación de la naturaleza, del pasado y la valoración del individualismo y la singularidad en una sociedad adocenada.

Por otro lado, la puesta en valor de determinados elementos culturales difiere de la simple activación o actuación sobre estos, en el sentido de que la primera depende fundamentalmente de los intereses de los poderes políticos y de la negociación con las fuerzas sociales, y de una previa puesta en valor jerarquizada de determinados elementos fruto de procesos identitarios. La activación en cambio gira en torno a discursos basados a su vez en una serie de reglas gramaticales, que serían la selección, ordenación e interpretación de los elementos integrantes de dicha activación. Es esta interpretación la que se erige en generadora del discurso y dirige la gestión del patrimonio bajo una aparente asepsia ideológica. 


\section{perifèria}

Número 7, Diciembre 2007

www. periferia. name

La negociación entre los poderes políticos y la sociedad tiene como finalidad alcanzar el máximo consenso para legitimar suficientemente el discurso subyacente a la activación y así este aparezca conforme a la realidad socialmente percibida. A impulsos de los intereses existentes, en ocasiones se recurre a la ficción de legitimar los elementos o los componentes en lugar del discurso, de forma que nos encontramos exposiciones, museos o parques de todo tipo, neutros únicamente en apariencia.

En la medida en que el patrimonio interioriza o vehiculiza elementos de la identidad, señas de identidad, hemos de aceptar que es un vehículo de expresión cultural y por tanto dinámico, cambiante, en definitiva popular y no reificado. Sin embargo, el desarrollo de pautas de consumo de ocio y turismo en las sociedades capitalistas ha dado lugar a un mercado lúdico-turístico-cultural basado en activaciones y restylings patrimoniales que tienden a la espectacularización y a la trivialización reduciendo ostensiblemente la polisemia de los elementos activados hasta el vaciamiento de significado, en favor de la sensación y la gratificación inmediata.

El proceso de valorización de las semillas locales ha tenido lugar desde dos lógicas contrapuestas y retroalimentadas. Por un lado, el interés económico que las multinacionales tienen sobre la biodiversidad y los conocimientos a esta ligados ha dado lugar a un proceso de patrimonialización de lo que estas empresas consideran como recursos genéticos, desde la idea de "ganancia" mercantil. Paradójicamente, la dependencia que de la biodiversidad tiene las multinacionales, ha llevado a alguna de ellas a crear bancos de semillas locales junto a confederaciones de agricultores industriales ${ }^{6}$, lo cual les permite a su vez un lavado de imagen de cara a la opinión pública.

\footnotetext{
6 La idea original es de Croplife International, pero es la multinacional Monsanto junto con la Confederación nacional de productores agrícolas industriales de Mexico, la que ha impulsado la creación de un banco de semillas autóctonas. Ver, Silvia Ribeiro en Berria 03-06-2007.
} 


\section{perifèria}

Número 7, Diciembre 2007

www. periferia. name

Por otro lado, la creación de bancos de semillas locales y las iniciativas de preservación de las comunidades indígenas y de agricultores locales en este sentido, tienen lugar en base a procesos de valorización de las semillas desde la idea de "pérdida". La conciencia de pérdida y de usurpación de ese patrimonio dispara la valoración del mismo como tal. La presión económica y el monopolio de las multinacionales han traído consigo de forma reactiva una puesta en valor por parte de estas comunidades.

Ambos procesos tiene lugar en torno a discursos de legitimación contrapuestos recreados en torno a las nociones de sostenibilidad, propiedad intelectual, preservación de la biodiversidad.

\section{Noción de Sostenibilidad y su Polisemia}

La biodiversidad, tomada hasta hace bien poco como un recurso inagotable, en la actualidad se considera un recurso en disminución y esta misma percepción de escasez ha generado una sobrevaloración de la misma desde diferentes sectores en conflicto, hasta el punto de que se habla de ella en términos de "valiosos organismos y sistemas de conocimiento", desde posiciones teóricamente contrarias. Para las industrias de la vida que usan sofisticadas técnicas biotecnológicas, los organismos vivientes y el conocimiento acerca de sus usos han llegado a ser valiosas mercancías explotables a través de derechos de propiedad intelectual. También los discursos proteccionistas se construyen desde esta valoración de la diversidad.

Los centros Vaviloven o grandes centros de diversidad genética (llamados así en honor al científico que los describió) se encuentran en el Sur y así tiene lugar un flujo continuo de genes de cultivos desde los campos de los agricultores del Sur hacia otros agricultores en el Norte, principalmente a través de programas internacionales de cooperación. $Y$ es que es básicamente en los campos del sur donde se retiene la diversidad genética fundamental para la seguridad alimentaria global y el conocimiento acumulado y profundo de las comunidades agrícolas, en millones de micro ambientes diversos. Las corporaciones han llegado a ser biopiratas en busca de tesoros biológicos encontrados sólo a través de los mapas 


\section{perifèria}

Número 7, Diciembre 2007

www. periferia. name

en el intelecto de las comunidades agrícolas, en muchas ocasiones con la notable colaboración de antropólogos. Este control de la diversidad tiene dimensiones éticas, económicas, culturales, ecológicas o sociales. La pérdida de las prácticas agrícolas va de la mano en un proceso complementario con la pérdida de la cultura y el lenguaje.

Hay por tanto interés por conservar las ecotecnologías de las comunidades rurales, de forma que se preserven las otras dimensiones que atañen al control de la biodiversidad, en vez de someter su conocimiento ecológico local y tecnológico de la agricultura y la biodiversidad a un sistema de agricultura industrial controlada externamente. Este interés no es solo de las propias comunidades sino también de las multinacionales pues paradójicamente han descubierto en estos sistemas que están esquilmando un filón de futuro.

A partir de la década de los ochenta el concepto de sostenibilidad se incorpora al vocabulario común. Se trata en opinión de Lins Ribeiro del concepto central de El gran metarrelato utópico del ambientalismo (Lins, 1991:84). La noción de sostenibilidad, en la que convergen el uso y la preservación, y caracterizada por la ambigüedad, se ha convertido con el tiempo en un campo discursivo susceptible de controversia y manipulable por diversas corrientes ideológicas y políticas económicas con programas divergentes y hasta antagónicos.

Esta ambigüedad se refleja en la polisemia del término y en su utilización en múltiples discursos con significados diversos (Peet \& Watts, 1996) sobre el declive ambiental y su explicación histórica. En los discursos de sectores enfrentados en el conflicto se apela a esta misma significación.

En los discursos gubernamentales y corporativos en general se apela a como rehacer la naturaleza de maneras congruentes con la sostenibilidad de las utilidades y la acumulación del capital (O'Connors, 2001). Se plantea una representación de esta en la que no se respetan los tiempos ecológicos de recuperación, reproducción y conservación, y la naturaleza aparece como un grifo, como un ineludible prerrequisito para la extracción de plusvalor de la fuerza de trabajo (Burkett, 1999), y un territorio de dinámicas a expropiar. Es en definitiva un discurso que se 


\section{perifèria}

Número 7, Diciembre 2007

www.periferia.name

enmarca en la tendencia del discurso de la sostenibilidad pero que apunta a lograr un crecimiento económico sostenible mediante mecanismos de mercado y donde ha desaparecido aquella contradicción excluyente entre crecimiento y medio ambiente (Hornborg, 2003).

Para las empresas multinacionales, la problemática ambiental se reduce a una crisis en los costos de producción, de forma que su discurso se enmarca en lo que se ha venido en llamar las propuestas ecologistas neoliberales que giran en torno a la noción de capital natural y desde donde se sostiene la idea de que los mecanismos de mercado son suficientes para internalizar los costos ecológicos de la explotación.

En los discursos de los agricultores por lo general se incide en dos variantes representacionales de esta noción de sostenibilidad, por un lado lo que O'Connor llama el sentido de la sostenibilidad basado en la idea primaria de proveer lo necesario para la vida, por parte de aquellos que ya han sido expropiados de sus condiciones de producción. Por otro basado en la idea de resistir sin ceder, por parte de aquellos cuya forma de vida está siendo alterada por las nuevas formas de la producción y los procesos macroeconómicos. En este sentido la naturaleza se presenta en este discurso como sustancia y nicho indispensable del desarrollo humano, y la crisis ecológica es construida como un deterioro general de las condiciones de desarrollo de la vida de las personas y especies naturales y a su vez el valor de uso de los recursos y productos aparece como elemento central a tener en cuenta.

\section{Antropologia y Medio Ambiente}

En opinión de la antropóloga irlandesa K: Milton (1997:16), dos han sido los motivos fundamentales que han propiciado el hecho de que la aportación de la antropología al discurso ambiental haya tenido escasa trascendencia hasta el momento. Por un lado, mientras la opinión pública miraba lo macro los antropólogos miraban lo micro. Durante mucho tiempo la preocupación pública por el entorno se ha centrado en actividades agrícolas e industriales a gran escala con consecuencias a nivel global, mientras los antropólogos han tendido a estudiar poblaciones pequeñas no industrializadas y relativamente autosuficientes. En 


\section{perifèria}

Número 7, Diciembre 2007

www. periferia. name

segundo lugar, la ecología humana, es un campo de estudio interdisciplinario lo cual ha provocado una dependencia académica de otras disciplinas y ha relegado a un segundo plano las contribuciones de los antropólogos.

Las críticas al relativismo a ultranza han posibilitado al antropólogo superar cierto escepticismo a la hora de participar de forma práctica en la reforma social y cultural para la búsqueda de soluciones a problemas medioambientales concretos y hacer de alguna forma más visible su aportación al problema. Una aportación que según la propia Milton, viene dada de dos formas: 1) una primera basada en el tipo de conocimiento que la antropología ha generado y 2) otra basada en las orientaciones teóricas de los antropólogos.

1) La tarea del antropólogo es comprender el papel de la cultura en las relaciones entre los seres humanos y el entorno y en este sentido resulta obvio que en la resolución de problemas ambientales es importante detectar los componentes culturales de aquella práctica de la gente que se quiere modificar en un sentido. Por tanto, por un lado la antropología aporta elementos para la comprensión de lo que significa un modo de vida sostenible no sólo desde el punto de vista de la utilización física del ambiente, sino desde el punto de vista de qué valores y formas de ver el mundo fomentan prácticas benignas o perjudiciales, y que prácticas fomentan a su vez determinados valores y cosmovisiones. Milton ilustra este argumento con un ejemplo concreto. El concepto de biodiversidad y el valor que le ha empezado a otorgar la ciencia occidental (en la mayoría de los casos estimulado por intereses mercantiles) han contribuido a legitimizar el control de los recursos locales tanto por parte de estados como de empresas comerciales (Shiva, 1993). Paradójicamente esta doctrina que se envanece en valorar el medio ambiente como patrimonio de toda la humanidad margina y esquilma las comunidades locales. Ingold (1993) sostuvo que el concepto de entorno global favorece los postulados de la ciencia occidental en detrimento de las perspectivas que ofrecen las culturas locales. Al describir el mundo como un todo, como un objeto fuera de nuestra comprensión, la ciencia nos dice que su conocimiento verdadero sólo puede obtenerse considerándolo desde fuera, a través de la observación distante. Por contra, las comunidades locales extraen su conocimiento sobre el entorno 


\section{perifèria}

Número 7, Diciembre 2007

\section{www.periferia.name}

experimentándolo desde dentro de él. A este respecto, dos posturas enfrentadas centran el debate ambiental en la actualidad entre aquellos que abogan por un control de los recursos de la tierra a nivel global basado en acuerdos internacionales, y aquellos que creen más legítimo dejar el control de sus propios recursos en manos de las propias comunidades locales (Milton, 1996).

Los argumentos aportados por los antropólogos de que las distinciones propias de la cultura occidental no son universales dentro del pensamiento humano y que los distintos modos de ver el entorno dan lugar a cosmovisiones particulares a la vez que se derivan de ellas, combinados con la noción, ampliamente expresada tanto por antropólogos como por ambientalistas de que todas las culturas, independientemente de su grado de veracidad, son dignas de respeto, añaden fuerza a una perspectiva localista (Milton 1997: 18).

En definitiva, en el mundo descrito por los antropólogos no existe una única ecología humana sino una multitud de distintas 'ecologías', producto de distintas formas de relacionarse con el medio. De esta manera, si la cultura es el mecanismo a través del cual los seres humanos interaccionan con sus entornos, al plantear los términos en que el conocimiento antropológico se aplica a la resolución de los problemas medioambientales, la diversidad cultural se torna en un elemento fundamental. La actuación sobre la diversidad no necesariamente ha de consistir en la preservación de lo que ya existe puesto que la creación de nuevos modos de comprender el medio ambiente podría también generar modelos de vida sostenibles.

2) Así, la aplicación del conocimiento antropológico a problemas prácticos, incluidos los problemas ambientales, también tiende a ignorar las tradicionales divisiones internas de esta disciplina, ya que son las consideraciones prácticas lo que define el campo de conocimiento pertinente. Si las aspiraciones políticas de una comunidad motivan a sus miembros para actuar de un modo ambientalmente pernicioso, son entonces las políticas concretas las que deben ser comprendidas y cambiadas; el hecho de que política, legislación, patrimonio y ecología hayan sido consideradas tradicionalmente campos de actividad distinta resulta ahora irrelevante. La antropología ecológica se disuelve dentro del todo una vez que queda 


\section{perifèria}

Número 7, Diciembre 2007

www. periferia. name

perfectamente establecido el carácter interactivo de la cultura.

\section{Antropologia, percepción del entorno y la dicotomía clásica naturaleza-cultura}

Además de describir como son las diferentes culturas, el objetivo de la antropología también es explicar por que estas culturas son distintas entre si, y en este sentido, los intentos de comprender como las distintas sociedades perciben e interpretan su entorno han aportado algunas cuestiones interesantes al respecto. Así, según propone K. Milton, podríamos dividir los modos de comprender el entorno en dos categorías principales: aquellos que ven los mundos humanos y no humanos como un continuo y aquellos que los seccionan, siempre contando con que es posible que ambos tipos existan dentro de la misma perspectiva cultural, con la humanidad colocada a veces dentro de la naturaleza y a veces fuera de ella (1997:14). Sin embargo, también parece ocurrir que algunas culturas han empleado tradicionalmente sólo una o predominantemente una de las dos formas posibles.

Hay cierto consenso entre los antropólogos a la hora de considerar que los modos de comprender el entorno, en definitiva las distintas perspectivas ambientales derivan de la forma de usarlo y estar inmerso en él. Atendiendo al planteamiento de Dwyer (Dwyer, 1996), un modelo extensivo del uso de los recursos, en el que la gente se familiariza con todos los aspectos de su entorno guarda cierta correspondencia con un punto de vista totalmente integrado del ambiente, en el que no hay ruptura entre los mundos humano y no humano. Por contra, una perspectiva que separe el mundo humano del no humano es más coherente con un modelo intensivo del uso de recursos, que concentra la actividad humana en el espacio.

Algunos investigadores han considerado, los modos de aprovechamiento de las plantas o de interaccionar con los animales no humanos, indicadores significativos de la formación de las perspectivas ambientales de la gente. En este sentido Coursey (Coursey, 1978) ya planteó la idea de que el cultivo de vegetales, la propagación de las plantas por injertos y replantación de tubérculos genera una actitud no intervencionista hacia el entorno en la que las actividades humanas se 


\section{perifèria}

Número 7, Diciembre 2007

www. periferia. name

consideran como parte del mismo sistema en tanto en cuanto son procesos no humanos. Por otro lado, el cultivo mediante semillas (más intensivo) requiere un enfoque más intervencionista que separe las actividades humanas de los procesos en que intervienen, evocando en cierta manera los planteamientos de Haudricourt (1964).

En las sociedades industriales, la agricultura intensiva ha llevado la intervención en los procesos naturales hasta límites extremos, a base de extensos monocultivos, pesticidas contra los parásitos naturales y la aportación de insumos químicos para revitalizar suelos estériles consecuencia de esas mismas prácticas. No es de extrañar que este modelo de relación con el medio se acompañe de una visión del mundo en la que naturaleza y cultura se oponen y se considere la dominación de la naturaleza por la cultura como el motor del progreso humano. Una campaña publicitaria ${ }^{7}$ lleva estos días hasta nuestra cotidianeidad doméstica todo este imaginario sobre la naturaleza resumido con esa capacidad de síntesis propia de los publicistas en dos simples eslóganes: porque la naturaleza es sabia pero no tanto y porque la naturaleza lo tiene todo, pero todo se puede mejorar.

Sin embargo, en el mismo seno de las sociedades industrializadas los conceptos de naturaleza son complejos y ambiguos, tal como cabe esperar que ocurra en toda sociedad cuyos miembros se relacionan con su entorno de modos muy variados y por tanto se generan distintas visiones y perspectivas del entorno.

La aportación del conocimiento antropológico al discurso ambiental contemporáneo va más allá de la idea determinista y unidireccional de que los modos de interactuar con el entorno moldean los modos de comprenderlo, planteando el proceso no como un proceso unidireccional sino dialéctico en el que los modos en que la gente comprende su entorno también moldean su modo de relacionarse con él. Por un lado la perspectiva cultural proporciona, conocimientos, valores, objetivos y una base ideológica para la actividad humana. La actividad, a su vez, retroalimenta la comprensión que la gente tiene del mundo, a través de experiencias y percepciones e interpretaciones.

\footnotetext{
${ }^{7}$ Se trata de una campaña de zumos de fruta con soja de una conocida marca.
} 


\section{perifèria}

Número 7, Diciembre 2007

www. periferia.name

La dicotomía naturaleza/cultura es una oposición clásica del pensamiento occidental moderno y su universalidad ha sido durante décadas motivo de discusión por la antropología post-estructural, Descola (1996); Ortner (1996); Strathern (1980); Valeri (1990). La reacción frente a las dicotomías modernistas ha vuelto a colocar el debate en el centro de atención de la disciplina. Un debate que gira principalmente en torno a cuestiones como, si esta oposición tiene más o menos el mismo significado en las distintas culturas del mundo, o si son nociones que existen como categorías definidas en todas las culturas o son más bien producto de los marcos universalizadores de la cultura occidental.

La relación entre ambos conceptos ha ido variando de significado a medida que los nuevos enfoques teóricos han ido reemplazando los antiguos. 1) El determinismo ambiental concebía la naturaleza y la cultura como entidades separadas, y se centraba en el modo en que la naturaleza actuaba sobre la cultura, considerando que la primera moldeaba de alguna forma la segunda. 2) El enfoque teórico basado en el concepto de ecosistema, manejaba ambos conceptos, naturaleza y cultura, como partes del mismo sistema integrado; separados pero siempre influyéndose entre sí. Naturaleza y cultura se hallaban en ambas corrientes claramente determinados en la mente del investigador, como parte del marco de referencia utilizado para dar sentido a sus datos (Milton, 1997:12). 3) La etnoecología daba por supuesto que estas categorías se hallaban presentes en las mentes de la gente de todas las culturas y se centraba en la manera en que naturaleza y cultura se relacionan en las mentes de la gente que estudiamos. Paralelamente a esta corriente cognitivista, se desarrolla el estructuralismo francés de Lévi-Strauss (1963), que postulaba la existencia de una estructura de pensamiento universal basada en oposiciones binarias (naturaleza-cultura, hembra-macho, frío-calor, noche-día, etc. ).

Los antropólogos de la década de los noventa, centran el debate en torno a si las categorías naturaleza y cultura son universales dentro del pensamiento humano o únicamente son categorías clasificatorias de la realidad que se manejan en algunas sociedades concretas. 


\section{perifèria}

Número 7, Diciembre 2007

www. periferia. name

Este argumento de que el concepto occidental de naturaleza no lo comparten todas las sociedades se basa en un modo determinado de definir la naturaleza como algo opuesto y excluyente de la cultura. Considerar la oposición mutua como premisa de la existencia de ambas nociones implica que la ausencia de uno de ellas, implicaría a su vez la ausencia de su opuesto. La experiencia etnográfica ha demostrado que la noción de naturaleza se halla ausente en algunas cosmovisiones. De igual forma ocurre con la noción de cultura. Para Dwyer (1996) la capacidad de una sociedad concreta para desarrollar un concepto de la naturaleza depende de si sus miembros consideran su entorno como un todo integrado o lo dividen en espacios que les resultan familiares y espacios que les resultan extraños. Dwyer sugirió que el tipo de entorno que experimentan los Kubo en la selva que habitan puede considerarse cultural ya que debe comprenderse en su totalidad, como un paisaje de acción e interacción humana (Milton, 1997:13).

Incluso si fuera una estructura universal como plantean los estructuralistas, que varía en distintas culturas, no tiene por qué estar planteada necesariamente como una relación de dominación o superioridad cultural sobre la naturaleza. Naturaleza puede ser una categoría de paz, belleza, armonía, autonomía, autorregulación o puede ser una categoría de violencia, destrucción, apatía o inercia. Igualmente ocurre con la noción cultura (Ortner, 1996). De todas maneras no estamos ante una especie de objeto empírico sino ante un supuesto de una relación que subyace a una variedad de superficies etnográficas.

Sherry Ortner plantea la oposición como uno de los acertijos más importantes que la humanidad tiene que resolver, planteado en términos de la confrontación entre humanidad y naturaleza, o en palabras de Strathern (1980), entre humanidad y aquellos procesos que ocurren de manera autónoma en el mundo y que limitan la posible acción del hombre ${ }^{8}$.

\footnotetext{
${ }^{8}$ Citado en Valeri, 1990: 266.
} 


\section{perifèria}

Número 7, Diciembre 2007

www. periferia. name

En lo que todos los pensadores que han planteado esta cuestión coinciden es que aunque no es universal, es una estructura bastante extendida y es una oposición muy propia del pensamiento occidental moderno y sobre la que se ha construido todo un modelo de pensamiento naturalista.

A pesar de esto, Ellen (1996) mostró que la noción de naturaleza manejada desde la propia cultura occidental es una noción polisémica y ambigua y no siempre opuesta a la de cultura, identificando tres sentidos distintos de entenderla: 1) como espacio que no es humano, en el mismo sentido en que lo usaban Ingold y Dwyer; 2) como una categoría de objetos excluyente de los productos humanos pero que también puede incluirlos, tal como ocurre en algunas afirmaciones realizadas por algunos activistas medioambientales en el sentido de que la humanidad forma parte de la naturaleza y las actividades humanas y sus consecuencias se hallan sujetas a las leyes naturales; y 3) como una esencia interior, aplicable tanto a seres humanos como a no humanos (Ellen, 1996). Ellen propone que un concepto de naturaleza que incorpore los tres significados puede constituir una base útil para la comparación intercultural.

Esta ontología naturalista característica de la modernidad supone una continuidad entre las diferentes formas de vida en el plano físico regido por las mismas leyes de materia y vida y reconoce a su vez la diversidad en manifestaciones individuales y colectivas. El problema central de esta epistemología se formula a través de la siguiente cuestión: ¿donde se sitúa la cultura en la universalidad de la naturaleza? El sujeto de conocimiento en el naturalismo es un sujeto abstracto que a diferencia del animismo, totemismo, o analogismo, excluye a los no-humanos de las formas superiores de conocimiento y acción, de forma que la posición del sujeto se confina una sola especie (Descola, 1996).

En definitiva se podría plantear que hay cierto consenso en la comunidad científica respecto a que la dicotomía Naturaleza/cultura, en este sentido específicamente occidental planteada como una lucha de dominación de la naturaleza por parte del hombre, no es una estructura de pensamiento universal, ni siquiera la idea de que naturaleza y cultura son dos objetos o categorías distintas Pero lo que si es universal es la relación entre lo que la humanidad puede hacer y lo que impone 


\section{perifèria}

Número 7, Diciembre 2007

www. periferia.name

límites a esas posibilidades, y las soluciones ante este dilema varían a lo largo de la historia y las diferentes culturas. Es una lógica que se basa en una construcción particular de la relación entre naturaleza y cultura, la idea de que la cultura debe consistir en trascender la naturaleza.

\section{Bibliografía}

Bonnemaison, Joachim (1981). Voyage autour du territoire. En L'espace Géographique, №4: 249-262.

Bonte, Pierre \& IZARD, Michael (1996). Diccionario Akal de Etnología y Antropología. Madrid: Ed. Akal.

Burkett, Paul (1999). "Marx and Nature: a Red and Green Perspective", Monthly Review Press. New York.

Coursey, D. G. (1978). Some ideological considerations relating to tropical root crop production. En, E. K. Fisk (ed.) The adaptation of traditional agriculture: socioeconomic problems of urbanization, Development Studies Centre Monograph 11. The Australian National University. Canberra.

Descola, Philippe y Pálsson, Gísh (eds.) (1996). Naturaleza y sociedad. Perspectivas antropológicas. México: Siglo XXI.

Di Méo, Guy (2000). Géographie sociale et territoires. Paris: Nathan.

Dwyer, P. D. (1996). “The Invention of Nature". En, R. F. Ellen y D. Fukui (eds) Redefining nature: ecology, culture and domestication. Oxford: Berg.

Ellen, Roy F. y FUKUI, Katsuyoshi (1996). Redefining Nature: Ecology, Culture and Domestication. Oxford: Berg.

Geertz, Clifford (2003). La interpretación de las culturas. Barcelona: Gedisa.

Gillies, Anne Ed. (1997). “Confinamientos de la razón. Monopolios Intelectuales. Un material de apoyo sobre conocimiento local, biodiversidad y propiedad Intelectual". The Rural Advancement Foundation International (RAFI). En, http://www. etcgroup.org/documents/other_confinamientos_es.pdf

Haudricourt, A.G. (1964). Nature et culture dans la civilisation I"igname: I’origine des clones et des clanes. Paris: Ed. L`homme. 


\section{perifèria}

Número 7, Diciembre 2007

www.periferia.name

Hornborg, Alf (2003). "Cornucopia or zero-sum game? The epistemology of sustainability", J ournal of World-Systems Research, IX(2): 205-216.

James, Allison (1993). Eating green(s). Discourses of organic food. En, Environmentalism. The view from anthropology, K. Milton (ed.) London: Routledge. Kästler, Guy (2005). “La legislación de semillas en Europa deja fuera a los agricultore", Biodiversidad, no46, Octubre. 34-46. GRAIN.

Kloppenburg, Jack (1988). First the seed. The political economy of plant biotechnology. Cambridge: Cambridge University Press.

Lins Ribeiro, Gustavo (1991). "Ambientalismo e desenvolvimento sustentado. Nova ideología/utopia do desnvolvimento", Revista de Antropología, Universidad de Sao Paulo.

Louwaars, Niels (2005). "Sesgos y cuellos de botella de las leyes de semillas". En, Biodiversidad, no46, Octubre. 5-11. GRAIN.

Meillassoux, Claude (1993). Mujeres, graneros y capitales. 10a ed. Siglo XXI editores.

Milton, Kay (ed.) (1993). Environmentalism: The view from Anthropology. London: Routledge.

Milton, Kay (1996). Environmentalism and cultural theory: exploring the role of anthropology in environmental discourse. London: Routledge.

Milton, Kay (1997). Ecologías: antropologias, cultura y entorno. En, Revista Internacional de Ciencias Sociales, ISSJ, Dic. Na154. Antropología-Temas y Perspectivas II. Explorar nuevos horizontes On line: http://www. unesco.org/issj/rics154/miltonspa.html. UNESCO.

O'Connor, James (2001). Causas naturales. Ensayos de marxismo ecológico. México: Siglo XXI.

Ortner, Sherry (1996). Making Gender: The Politics and Erotics of Culture. Boston: Beacon Press.

Peet, Richard \& Watts, Michael (eds.) (1996). Liberation ecologies. Environment, development, social movements. London: Routledge. 


\section{perifèria}

Número 7, Diciembre 2007

www.periferia.name

Prats, Llorenç (1997). Antropologia y patrimonio. Ed Ariel Antropologia. Barcelona.

Prats, Llorenç (2005). "Concepto y gestión del patrimonio local". En, Cuadernos de Antropología Social, no 21. 17-35. Universidad de Barcelona.

Ribeiro, Silvia (2007). "Monsanto eta artoaren suntsiketa (Monsanto y la destrucción del maíz)". En, Berria 03-06-2007.

Rodriguez Cervantes, Silvia (2006). "TLCs: El conocimiento tradicional en venta". En, Grain.

Shiva, Vandana (1994). Monocultivos y biotecnología. Red del Tercer Mundo. Uruguay.

Shiva, Vandana et al. (1995). The seed keepers. Nueva Delhi: Navdanya.

Shiva, Vandana (2001). Biopiratería: el saqueo de la naturaleza y del conocimiento. Barcelona: Ed Icaria.

Shiva, Vandana (2003). Cosecha robada. El secuestro del suministro mundial de alimentos. Barcelona: Paidós.

Strathern, Marilyn (1980). "No Nature, No culture: The Hagen Case". En Nature, Culture and Gender. Carol P. MacCormack y Marilyn Strathern, Eds. Cambridge University Press. Cambridge.

Valeri, Valerio (1990). "Both Nature and Culture: Reflections on Menstrual and Parturial Taboos in Huaulu (Seram)". En Power and Difference: Gender in Island Southeast Asia. Jane Atkinson y Shelly Errington, Eds. Stanford: Stanford University Press.

Wan Ho, Mae (2001). Ingeniería genética: ¿sueño o pesadilla? Gedisa. Barcelona. 